\title{
Do adolescents with long-term illnesses and disabilities have increased risks of sports related injuries?
}

\author{
Kwok W. Ng ${ }^{*}$, Jorma Tynjälä, Pauli Rintala, Sami Kokko and Lasse Kannas
}

\begin{abstract}
Background: The aim of this study is to examine the rates of sports related injuries in adolescents based on the severity of their long-term illnesses or disabilities (LTID). Few injury prevention strategies in sports and health promotion have explored disaggregation by disability.

Methods: Data obtained from the 2014 Finnish Health Behaviour in School-aged Children survey $(n=3716$, mean age $=14.8, S D=1.03$ ) were grouped into adolescents with and without LTID. A further indicator or severity was determined when adolescents reported their LTID affected their participation (affected LTID). Odds ratio (95\% CI) were used to determine the associations between sports related injuries and LTID, daily moderate to vigorous physical activities (MVPA), being a sports club member, physical competence, and family encouragement, after controlling for age, gender and family affluence.
\end{abstract}

Results: One in four adolescents (25\%) reported to have LTID and one in eight adolescents (12.5\%) reported sports injuries. The odds for adolescents with chronic conditions, functional and learning difficulties was the highest (OR 3. $55, \mathrm{Cl}=2.3-5.4)$ for overall injuries, when compared with adolescents without LTID. Adolescents with affected LTID $(\mathrm{OR}=2.08, \mathrm{Cl}=1.5-2.9)$ were more likely to report medically attended injuries than adolescents without LTID. Sports-related injuries $(\mathrm{OR}=0.33, \mathrm{Cl}=0.1-0.8)$ were lower in adolescents with affected LTID than those without LTID after adjusting for personal and environmental factors.

Conclusions: Taking part in sport clubs increases the risk of sports related injuries in adolescents with and without LTID, but not with affected LTID. Few adolescents with affected LTID participate in sports clubs and were less likely to report the most serious type of injury to be from sports. These results could be used for devising sports based injury prevention and health promotion strategies for children with LTID.

Keywords: Disability, Chronic disease, Safety promotion, Physical activity, Organised sports, Health behaviours

\section{Background}

Taking part in physical activities (PA) during adolescents is essential in the fight against obesity, to gain physiological and mental health benefits, as well as opportunities for youth social engagement in organised sport settings (WHO, 2010). This is even more important in adolescents with long-term illnesses or disabilities (LTID), since regular participation in PA can reduce the onset of secondary conditions to existing LTID (Rimmer et al. 2012). However, a critical consideration that researchers, professionals, parents, and individuals interested in promoting

\footnotetext{
* Correspondence: kwok.ng@jyu.fi

University of Jyvaskyla, PO Box 35 (L), 40014 Jyvaskyla, Finland
}

PA for health is the heightened risk of injuries through sports (Mitchell et al. 2010).

Recent meta-analysis of 15 studies with a total sample size of 9,581,553, including 83,286 adolescents with LTID, reported more injuries than their counterparts without LTID and the difference increases as the children get older (Shi et al. 2015). In addition, adolescents who reported more LTID conditions were at even greater risks of medically attended injuries (Raman et al. 2007). Numerous studies have reported the higher threat of sports related injuries among adolescents with LTID than the general participation (Shi et al. 2015). However, it is not clear if this is the same for all adolescents with 
LTID or if it is more common in specific types of conditions. Studies have reported injuries in adolescents with autism and history of seizures are more common than other conditions (Ramirez et al. 2004; Ramirez et al. 2009). Yet, the fear of injuries are commonly reported among adolescents with LTID (Bloemen et al. 2015) thus acts as barriers for PA participation (Pittet et al. 2009). Other modifiable factors that may influence the risk of injuries include individual physical condition, proprioception as well as physical competence (Emery 2003). Injury prevention programs targeted towards improved conditioning and balance training have increased exponentially between the 1970s and 2009 (Klugl et al. 2010). As such, the perceptions of physical competence are associated with levels of PA (Ng et al. 2016a) and may confound its associations with injuries.

Another contextual factor for exposure to sports related injuries is the environment they are in. Since young adolescents are under the care of their parents, the known risks of injury through sport may induce protective behaviours by the parents. Parents may feel it necessary to prevent injury by excluding their children with LTID from PA participation. Another environment that modifies injury risk at international level is the country. Clinical data provided by the Finnish Institute of Health and welfare (THL) indicates that injuries from sports are the 2nd most common form of emergency department hospitalisation between 10 and 14 year olds. The rate of injuries also increases during these ages and reaches a peak at the age of 15 (Mattila et al. 2004). Through international comparative non-clinical data, the association between the inequality gap, as measured by family affluence, and prevalence of medically treated injuries was the highest in Finnish boys in the international 2010 (Currie et al. 2009) and 2014 reports (Inchley et al. 2013). Similarly, studies have also reported the link between high family affluence and greater amounts of physical activity (Borraccino et al. 2009). Therefore, it was not surprising that data collected from the crossnational Health Behaviours in School-aged Children (HBSC) study revealed that just over half of medically treated injuries were through sporting activities (Pickett et al. 2005). Since the bottom end of the equity gap for PA is the smallest in Finland (Chzhen et al. 2016), it is important to study the associations in sports and injuries in Finland as this could negate the influence of family affluence. Therefore the purpose of this study is to investigate sports related injuries in relation to the severity of LTID, PA levels, sports club membership, physical competence, and family encouragement, after controlling for age, gender and family affluence. To proceed with this purpose, there are two parts to this study. The first part was to categorise adolescent with LTID and define the association with medically attended injuries. Following this, contextual factors were examined in relation to sports related injuries.

\section{Methods \\ Sampling and procedures}

This study is part of the Finnish version of the Health Behaviours in School-aged Children (HBSC) study. Adolescents $(n=3716)$ from schools all around Finland were included to generate a national representative sample consisted of only 13 and 15 year olds, with a response rate of $84 \%$ of 13 year olds and $86 \%$ of 15 year olds. The procedures of data collection followed the international HBSC study protocols (Roberts et al. 2009). Selected schools were randomly selected through two levels, regions of Finland (Capital, South, Middle, North), and type of area (urban, sub-urban, rural) using proportion probably size. The primary sampling unit was the school. According to the international HBSC protocol, schools had to come from the Finnish general education school setting, therefore private schools and special educational needs schools were not included. School principals agreed to permit pupil participation through passive consent and the study had ethical approval by the $\mathrm{Na}$ tional Board of Education in Finland at the beginning of the study. The survey was completed anonymously and voluntarily through pen and paper during the spring of 2014.

\section{Instruments \\ Long term illness or disabilities}

Two items from the chronic conditions short questionnaire (CCSQ) (Dale \& Marsh 1993) were used in this analysis to identify the health condition and impairment domains of the International Classification of Functioning, Disability and Health (ICF) (WHO 2001); "Do you have a long-time disability, illness or medical condition (such as cerebral palsy, diabetes, arthritis or an allergy) diagnosed by a doctor?" Responses were "Yes" and "No. The second item; "Does your long-term illness or disability affect your participation in school?" had response categories of "I do not have long-term illness or disabilities", "yes", and "no" was also included. Severity of disability was defined at three levels; (1) no disabilities (no LTID), (2) disabilities, but does not affect their participation in school (LTID), (3) disabilities with affecting participation in school (affected LTID). Both items have been developed from population surveys aimed at measuring disabilities (McDougall \& Miller 2003).

\section{Health conditions}

Following from completion of CCSQ, three categories of health conditions were measured; chronic conditions, learning difficulties and functional difficulties (Table 1). Items were from two item sets. One item set was for 
Table 1 The types of long-term illnesses or disabilities (LTID) and Chi-square test of independence in the proportion that LTID affects the individual's participation

\begin{tabular}{llcll}
\hline & $\begin{array}{l}\text { LTID } \\
(\%)\end{array}$ & $\begin{array}{l}\text { Affected LTID } \\
(\%)\end{array}$ & $\mathrm{n}^{\mathrm{a}}$ & $p_{\text {-value }}$ \\
\hline None & 88.0 & 12.0 & 125 & 0.158 \\
Chronic condition & 81.7 & 18.3 & 546 & 0.052 \\
Allergies & 83.1 & 16.9 & 391 & 0.688 \\
Asthma & 75.9 & 24.1 & 187 & 0.002 \\
Diabetes & 75.0 & 25.0 & 64 & 0.051 \\
Epilepsy & 29.4 & 70.6 & 17 & $<.001$ \\
Joint pains & 69.4 & 30.6 & 216 & $<.001$ \\
Learning difficulties & 72.2 & 27.8 & 252 & $<.001$ \\
Remembering & 69.8 & 30.2 & 149 & $<.001$ \\
Concentrating & 70.0 & 30.0 & 180 & $<.001$ \\
Sitting still & 69.0 & 31.0 & 113 & $<.001$ \\
Functional difficulties & 67.9 & 32.1 & 218 & $<.001$ \\
Breathing & 63.7 & 36.3 & 113 & $<.001$ \\
Handling objects & 44.4 & 55.6 & 27 & $<.001$ \\
Hearing & 52.9 & 47.1 & 17 & 0.001 \\
Moving & 47.6 & 52.4 & 63 & $<.001$ \\
Seeing & 67.9 & 32.1 & 53 & 0.001 \\
Speaking & 66.2 & 33.8 & 65 & $<.001$ \\
Overall & 83.7 & 16.3 & 942 & \\
\hline
\end{tabular}

LTID Long term illnesses or disabilities

* Pearson's Chi-square test of independence

${ }^{\text {a }}$ Columns are dominator for \%. Overall totals do not add up due to multiple conditions and difficulties per individual case

functional and learning difficulties, "Tick only one box that best describes you, using the following descriptors; Do you have difficulty.... (a) in seeing, even with glasses, (b) in hearing, even with a hearing aid, (c) in speaking fluently, (d) in moving, (e) in handling objects, (f) in breathing, for example, shortness of breath, (g) in remembering things, (h) in concentrating, (i) in sitting still during lessons." Response categories were used to measure severity included (1) No difficulties, (2) Difficulties do not affect functioning, (3) Difficulties affect functioning somewhat, (4) Difficulties affect functioning a lot, (5) Difficulties affect functioning very much. In line with the coding of the ICF (Selb et al. 2015), any items a-f with severities from 3 to 5 were grouped as functional difficulties. Any items g-i with severity from 3 to 5 were grouped as learning difficulties.

Health conditions are recognised as an independent domain in the ICF (WHO 2001). In the first item of the CCSQ, there were examples of LTIID "(such as ... diabetes, arthritis or an allergy)". These examples are not actual functional difficulties, yet seem to influence the way respondents self-identify themselves to have LTID. In previous rounds of HBSC, more than half of adolescents with LTID had conditions that were not functional ( $\mathrm{Ng}$ et al. 2014). To measure severity of the condition in line with the examples in the CCSQ and the ICF qualifiers, the measurement of frequency of symptoms related to diabetes, arthritis, allergy and epilepsy were used. These items were used an extension the HBSC health complaints checklist (Haugland \& Wold 2001), "How often have you had the following symptoms over the past 6 months? Tick one box for each symptom. (a) epileptic seizure symptoms, (b) allergy related symptoms, (c) diabetic symptoms caused by low or high blood sugar levels, (d) asthmatic symptoms such as wheezing, (e) severe joint pains (other than growing pains). Response categories included, (1) Almost daily, (2) More than once a week, (3) Approximately once a week, (4) Approximately once a month, (5) Less or never." Symptoms frequency of at least once a week was grouped as 'Chronic Conditions'. Observations of each LTID groups were combined to indicate co-existence of chronic conditions, functional difficulties and learning difficulties.

\section{Sports injuries}

Measures of medically attended injuries were derived from the 1988 Child Health Supplement to the U.S. National Health Interview Survey (Scheidt et al. 1995) and have been well validated and reliability ascertained from earlier international studies (de Looze et al. 2012; Molcho et al. 2006). The item included; "How many times during the past 12 months have you been injured so that you have been treated by a doctor or a nurse?" Responses included (1) I have not been injured over the last 12 months, (2) Once, (3) Twice, (4) Three times, (5) Four or more times.

Location of injury item has been used in the HBSC study in 1997 (Pickett et al. 2005) with the question; "Where were you when the most serious injury happened? Please tick the most appropriate box." Possible responses included, (1) I have not been injured in the past 12 months, (2) At home / in yard, (3) School during school hours, (4) School after school hours, (5) At a sports facility or field (not school), (6) In the street / road / car park, (7) Somewhere else.

Injury activity item, with a similar methodological history as the location of injury item (Pickett et al. 2005); "What were you doing when the most serious injury happened? Please tick the most appropriate box." Responses options included, (1) I have not been injured in the past 12 months, (2) I was riding a bike, (3), I was playing or training for sports or a hobby, (4), I was walking/running (excluding training for team sports or competitive sport), (5), I was driving or riding a moped car or other motor vehicle, (6), I was fighting, (7) I was doing paid or unpaid work, (8), I did something else. 
For the analyses in this study, several steps were taken to create a variable named, sports related injuries. First, pupils that indicated that they had at least one medically attended injury in the last 12 months were included in the sports related injury analysis. There were three groups of sports related injuries. Pupils that selected "at a sports facility or field (not school)" from the injury location item were used to identify serious injuries at a sports facility. Pupils that selected "I was playing or training for sports or a hobby" from the injury activities item were used to identify serious injuries while doing sports. Pupils that selected both "at a sports facility or field (not school)" and "I was playing or training for sports or a hobby" were used to identify serious injuries while doing sports at sports facility.

\section{Physical activities}

Moderate to vigorous physical activities The selfreporting measure of at least $60 \mathrm{~min}$ of moderate to vigorous physical activity was used (Prochaska et al. 2001). It consists of a single item asking the pupils how many days $(0-7)$ in the past week they were physically active for $60 \mathrm{~min}$ or more (cumulative). Two groups were created based on the moderate to vigorous physical activity (MVPA) recommendations for adolescents set at every day (daily) and less than 7 days (not daily) (WHO, 2010). The measure has moderate validity and good reliability in Finnish adolescents (Vuori et al. 2005).

Sports club Pupils were asked whether they belong and practice in a sports club or not. The response options included "not a member", "a member but not active", "a member and active", grouped as non-member, inactive, and active members, respectively. The nature of the analysis was to examine active members in an environment related to sports injuries, therefore the inactive members were grouped together with not members. The item has been used in national monitoring surveys for many years (Vuori et al. 2004).

Physical competence A single item that measured perceived physical competence was worded in the following way, "how good are you at sports compared to others the same age as yourself?" Response categories included "among the best", "Good", "Average", "Below average". Responses with average and below average were grouped into "low competency" group and good and among the best into the high competency group. The reliability of the item is sufficient in Finnish adolescents (Lintunen et al. 1995).

Family support During a typical week: how often your parents (or guardians)... "encourage you take part in physical activities or sports". Response categories were, "never", "rarely", “sometimes", “often", "very often”. In the analysis, frequent family support was considered when responses were "often" and "very often", and the infrequent support included "never", "seldom", and "sometimes". Reliability and validity studies are lacking on this particular question, although almost half of the adolescents (48.0\%) responded frequent family support.

\section{Family affluence scale}

The Family Affluence Scale III (FAS III) is a composite indicator of self-reported socio-economic status that includes six items of material wealth (number of holidays taken during the last year, dishwasher in the house, family car ownership, having one's own bedroom, number of bathrooms in the house, computer ownership). A collective sum score was created to then divide into three equal groups of low, medium and high family affluence, as replicated in an international validation study of the FASIII (Torsheim et al. 2015).

\section{Analysis}

The data file was cleaned for missing data. T-tests of injury frequency and MVPA were not statistically significant from completed data. Imputation of missing data was not necessary and the cases were removed. Descriptive statistics were used to report the prevalence of LTID, LTID classification, and severity of LTID by gender. Frequencies and cross-tabulations were used to compare the prevalence of the types of conditions between the groups of adolescents without, with and with affected LTID. Reported injuries in the last year were also compared through Chi-square test of independence statistics. Statistical significance was set at $\mathrm{p}<0.05$ with IBM SPSS 20.0.

Associations between LTID severity and injury types were examined using multiple logistic regression to estimate adjusted odds ratio (OR) and its 95\% confidence intervals (CI). Separate models were conducted for three types of injuries, (i) serious injuries at a sports facility, (ii) serious injuries while doing sports, iii) serious injuries while doing sports at sports facility. Included into these models were MVPA, sports club membership, physical competence, family encouragement, FAS, gender and age.

\section{Results}

A total of 3665 students (mean age $=14.8$ years, $S D=$ 1.03) were included in the 2014 Finnish HBSC study. There were slightly more girls $(51 \%)$ than boys $(49 \%)$ in the sample. One in four $(n=942 / 3665)$ reported to have a LTID, of which $16 \%(n=154 / 942)$ or $4 \%(n=154 /$ 3665 ) of the total reported to have LTID that affects their daily participation. This latter group is referred to as the group with affected LTID. Table 1 contains information on the measures used in this study based on 
whether or not the individual reported a medically attended injury or not. The denominator for the percentages was the sample size for each value of interest.

In spite of the fact the adolescent reported to have LTID, information from the scales used was not able to identify the condition in $13 \%$ of the sample. Half of the adolescents with LTID $(n=465 / 942)$ reported to have only chronic conditions, while a third $(n=306 / 942)$ reported coexistence of chronic conditions with functional difficulties, chronic conditions with learning difficulties, or chronic conditions with functional difficulties and with learning difficulties. Less than a one in seven adolescents with LTID $(n=125 / 942)$ reported no functional difficulties, chronic conditions or learning difficulties listed in the survey questionnaire (Table 2). These

Table 2 Descriptive statistics of no injuries and at least one injury in last 12 months

\begin{tabular}{|c|c|c|c|c|}
\hline & No injuries & $\begin{array}{l}\text { At least } \\
\text { one injury }\end{array}$ & $\mathrm{n}$ & $p$-value \\
\hline & $(\%)$ & $(\%)$ & & \\
\hline LTID & & & & $<.001$ \\
\hline No LTID & 64.0 & 36.0 & 2723 & \\
\hline LTID & 53.3 & 46.7 & 788 & \\
\hline Affected LTID & 46.1 & 53.9 & 154 & \\
\hline Gender & & & & $<.001$ \\
\hline Boy & 57.8 & 42.2 & 1772 & \\
\hline Girl & 64.1 & 35.9 & 1893 & \\
\hline Age category & & & & 0.654 \\
\hline 13 & 60.7 & 39.3 & 1759 & \\
\hline 15 & 61.4 & 38.6 & 1906 & \\
\hline Family Affluence Scale III & & & & $<.001$ \\
\hline Low & 67.4 & 32.6 & 482 & \\
\hline Medium & 63.4 & 36.6 & 2104 & \\
\hline High & 54.0 & 46.0 & 1016 & \\
\hline Sports Club Member & & & & $<.001$ \\
\hline Not Member & 69.6 & 30.4 & 2048 & \\
\hline Member & 50.4 & 49.6 & 1477 & \\
\hline Daily MVPA & & & & $<.001$ \\
\hline Not Daily & 64.4 & 35.6 & 2879 & \\
\hline Daily & 49.1 & 50.9 & 786 & \\
\hline Physical Competence & & & & $<.001$ \\
\hline Low & 68.2 & 31.8 & 1568 & \\
\hline High & 55.8 & 44.2 & 2097 & \\
\hline Family Encouragement & & & & $<.001$ \\
\hline Infrequent & 64.7 & 35.3 & 1909 & \\
\hline Frequently & 57.1 & 42.9 & 1756 & \\
\hline
\end{tabular}

LTID Long term illnesses or disabilities, MVPA Moderate to vigorous physical activity

* Pearson's Chi-square test of independence proportions did not vary by age group, gender or family affluence (FAS III). There were no differences in the number of sports club members between adolescents with (45.5\%) and without LTID (41.7\%), yet there were significantly $(\mathrm{p}<.001)$ less members that had affected LTID (27.6\%).

\section{Rates of medically attended injury}

A total of 1448 students (39\%) reported one or more medically attended injuries during the 12 months prior to completing the survey (Table 3 ). These injuries included sports related injuries as well as other types. Over half of sports club members (54\%) reported medically attended injuries. Adolescents with affected LTID reported significantly more medically attended injuries $(M$ $=2.22$, CI:1.99-2.45) than their peers with LTID $(\mathrm{M}=$ 1.82, CI:1.74-1.90) in the last 12 months. Adolescents without LTID reported significantly less number of medically attended injuries $(\mathrm{M}=1.58, \mathrm{CI}: 1.55-1.74)$ in the last 12 months.

\section{Sports related injury activity and location}

Over half of the adolescents that reported medically attended injuries stated that their most serious injury happened while playing or training (52.9\%). However, significantly $(\mathrm{p}<.001)$ fewer adolescents with affected LTID (29.0\%) stated playing or training in sports as the activity of the most serious injury. In addition, serious injuries from walking or running were generally low (3.8\%), and there were no statistical differences between LTID groups.

A third of adolescents that reported the most serious injury took place at the sports facility at the time of injury (34.7\%). Nevertheless, there were significantly ( $p$ $=.018)$ less adolescents with affected LTID (19.7\%) that were injured at a sports facility. Other common places for injuries for adolescents with affected LTID included

Table 3 Distribution of the groups of long-term illnesses or disabilities (LTID) and LTID status (\%)

\begin{tabular}{lllll}
\hline & $\mathrm{n}$ & LTID & Affected LTID $^{\mathrm{a}}$ & $p$-value \\
\hline None & 125 & 14.0 & 9.7 & 0.158 \\
Functional & 7 & 0.8 & 0.6 & 0.882 \\
Learning & 22 & 2.3 & 2.6 & 0.814 \\
Learning and Functional & 17 & 1.3 & 4.5 & 0.005 \\
Chronic & 465 & 53.4 & 28.6 & $<.001$ \\
Chronic and Functional & 93 & 8.8 & 15.6 & 0.009 \\
Chronic and Learning & 112 & 11.5 & 13.6 & 0.464 \\
Chronic, Learning, and Functional & 101 & 8.0 & 24.7 & $<.001$ \\
Total (n) & 942 & 788 & 154 & \\
\hline
\end{tabular}

n (sample size) - denominator, LTID Long-term illnesses or disabilities

* Chi-square test of independence of LTID types and status

a sum equals $99 \%$ since Affected LTID Column is rounded to 1 decimal point 
at home (23\%) and at school during school hours (21\%) (Table 4).

\section{Relationships between disability status and injury}

The odds for reporting a medically attended injury is double for adolescents with affected LTID, and one and a half times for adolescents with LTID than their peers without LTID (Table 5). Furthermore, adolescents with symptoms from chronic conditions were between 1.6 and 3.6 times more likely to report medically attended injuries. Adolescents with chronic conditions, learning difficulties and functioning difficulties had the highest odds of almost four times when compared to adolescents without LTID.

Adolescents without LTID were three times more likely to report injuries at a sports facility during practice or training for sports than adolescents with affected

Table 4 Injury characteristics (\%) for each long-term illnesses or disabilities status

\begin{tabular}{|c|c|c|c|c|}
\hline & $\begin{array}{l}\text { No } \\
\text { LTID }^{a}\end{array}$ & $\mathrm{LTID}^{\mathrm{a}}$ & $\begin{array}{l}\text { Affected } \\
\text { LTID }^{a}\end{array}$ & $p$-value* \\
\hline Place when injury happened & & & & $<0.001$ \\
\hline No Injury & 60.2 & 49.1 & 44.2 & \\
\hline At home/yard & 7.2 & 11.0 & 13.0 & \\
\hline School during school hours & 5.6 & 5.7 & 11.7 & \\
\hline School after school hours & 1.1 & 2.3 & 2.6 & \\
\hline Sports facility & 13.5 & 18.4 & 11.0 & \\
\hline Street & 5.3 & 4.4 & 7.8 & \\
\hline Other & 7.0 & 9.0 & 9.7 & \\
\hline Missing cases & 0.0 & 0.0 & 0.0 & \\
\hline Activity during injury & & & & $<0.001$ \\
\hline No Injury & 60.7 & 49.0 & 42.2 & \\
\hline Biking & 3.1 & 2.5 & 3.9 & \\
\hline Playing or training & 19.4 & 24.4 & 13.6 & \\
\hline Walking/ running & 1.2 & 2.4 & 3.9 & \\
\hline Riding/ driving in a car & 2.2 & 2.9 & 6.5 & \\
\hline Fighting & 0.9 & 0.5 & 4.5 & \\
\hline Work & 0.4 & 0.5 & 1.3 & \\
\hline Other activity & 11.6 & 17.6 & 23.4 & \\
\hline Missing cases & 0.4 & 0.1 & 0.6 & \\
\hline $\begin{array}{l}\text { Injured and sports club } \\
\text { membership }\end{array}$ & & & & $<0.001$ \\
\hline Not member & 56.3 & 51.9 & 68.2 & \\
\hline Member & 40.2 & 43.3 & 26.0 & \\
\hline Missing cases & 3.4 & 4.8 & 5.8 & \\
\hline
\end{tabular}

LTID (Long-term illnesses or disabilities)

No LTID (no reported LTID), LTID (yes, LITD), affected LTID (LTID and affects participation)

*Pearson's Chi-square test of independence

a 2723 adolescents without LTID, 788 adolescents with LTID, and 154

adolescents with affected LTID as the denominators
Table 5 Adjusted odds ratio (OR) and 95\% confidence intervals from binary logistic regressions for the association between medically attended injuries in the past 12 months and LTID status and groups

\begin{tabular}{lllll}
\hline & $\mathrm{n}$ & $\mathrm{OR}$ & Lower Cl & Upper Cl \\
\hline LTID Status & & & & \\
No LTID & 2723 & 1.000 & & \\
LTID & 788 & $\mathbf{1 . 5 5 9}$ & $\mathbf{1 . 3 2 8}$ & $\mathbf{1 . 8 3 0}$ \\
Affected LTID & 154 & $\mathbf{2 . 0 8 2}$ & $\mathbf{1 . 5 0 2}$ & $\mathbf{2 . 8 8 5}$ \\
Groups of LTID & & & & \\
None & 2848 & 1.000 & & \\
Functional & 7 & 1.352 & 0.302 & 6.054 \\
Learning & 22 & 1.503 & 0.647 & 3.490 \\
Learning \& Functional & 17 & 0.984 & 0.363 & 2.667 \\
Chronic & 465 & $\mathbf{1 . 6 0 5}$ & $\mathbf{1 . 3 1 7}$ & $\mathbf{1 . 9 5 6}$ \\
Chronic \& Functional & 93 & $\mathbf{2 . 1 9 0}$ & $\mathbf{1 . 4 4 5}$ & $\mathbf{3 . 3 1 8}$ \\
Chronic \& Learning & 112 & $\mathbf{1 . 6 7 9}$ & $\mathbf{1 . 1 5 0}$ & $\mathbf{2 . 4 5 1}$ \\
Chronic, Learning \& Functional & 101 & $\mathbf{3 . 5 5 3}$ & $\mathbf{2 . 3 3 5}$ & $\mathbf{5 . 4 0 7}$ \\
\hline
\end{tabular}

Bold text showing statistically significant results

LTID Long-term illnesses or disabilities

n (Sample size), OR (Adjusted Odds Ratio), Lower Cl (Lower 95\% Confidence Interval), Upper Cl (Upper 95\% Confidence Interval)

LTID (Table 6). The associations between adolescents with LTID and injuries while training for sports and injuries at a sports facility were significantly greater than adolescents without LTID. In addition, the association between injuries at a sport facility were six times higher for sports club members than non-members. Adolescents with high perceived physical competence and frequent encouragement by parents reported greater risks in sports related injuries.

\section{Discussion}

More conditions and severity, and more likelihood of injuries

The first part of this study examined medically attended injuries among adolescents with and without LTID from a national representative sample in Finland. Adolescents with LTID are more likely to report medically attended injuries and the odds increases to just over two times if the LTID affects their daily participation. In addition, of the three LTID classifications, adolescents with chronic conditions had significantly increased odds of reporting medically attended injuries. These findings concur with existing literature as rates of injuries in adolescents with specific conditions more common than other conditions (Ramirez et al. 2004; Ramirez et al. 2009).

The findings from this study continue to provide evidence that adolescents with LTID are at greater risk of injuries than adolescents without LTID (Shi et al. 2015; Mattila et al. 2004). The design of the study is original as it used data collected from general school systems to 
Table 6 Adjusted odds ratio (OR) and 95\% confidence intervals from binary logistic regressions for sports related injuries

\begin{tabular}{|c|c|c|c|c|c|c|c|c|c|c|c|c|}
\hline & \multicolumn{4}{|c|}{ Injury from training for sports $(n=3513)$} & \multicolumn{4}{|c|}{ Injury at sports facility $(n=3525)$} & \multicolumn{4}{|c|}{ Injury from training for sports at facility $(n=1507)$} \\
\hline & $\mathrm{n}$ & OR & Lower Cl & Upper Cl & $n$ & OR & Lower Cl & Upper Cl & $n$ & OR & Lower Cl & Upper Cl \\
\hline \multicolumn{13}{|l|}{ LTID Status } \\
\hline No LTID & 2620 & 1.000 & & & 2630 & 1.000 & & & 1044 & 1.000 & & \\
\hline LTID & 749 & 1.273 & 1.032 & 1.571 & 750 & 1.394 & 1.098 & 1.771 & 378 & 1.076 & 0.805 & 1.438 \\
\hline Affected LTID & 144 & 0.864 & 0.507 & 1.472 & 145 & 1.032 & 0.551 & 1.932 & 85 & 0.333 & 0.142 & 0.777 \\
\hline \multicolumn{13}{|c|}{ Sports Club Member } \\
\hline Not Member & 2041 & 1.000 & & & 2048 & 1.000 & & & 718 & 1.000 & & \\
\hline Member & 1472 & 4.112 & 3.363 & 5.029 & 1477 & 6.267 & 4.848 & 8.102 & 789 & 6.553 & 4.808 & 8.932 \\
\hline \multicolumn{13}{|l|}{ MVPA } \\
\hline Not Daily & 2760 & 1.000 & & & 2768 & 1.000 & & & 1096 & 1.000 & & \\
\hline Daily & 753 & 1.335 & 1.089 & 1.636 & 757 & 1.369 & 1.092 & 1.717 & 411 & 1.139 & 0.863 & 1.504 \\
\hline \multicolumn{13}{|c|}{ Physical Competence } \\
\hline Low & 1516 & 1.000 & & & 1520 & 1.000 & & & 547 & 1.000 & & \\
\hline High & 1997 & 1.769 & 1.432 & 2.186 & 2005 & 2.167 & 1.663 & 2.822 & 960 & 2.243 & 1.633 & 3.081 \\
\hline \multicolumn{13}{|l|}{ Family Support } \\
\hline Infrequent & 1832 & 1.000 & & & 1836 & 1.000 & & & 719 & 1.000 & & \\
\hline Frequent & 1682 & 1.317 & 1.095 & 1.585 & 1689 & 1.440 & 1.160 & 1.787 & 788 & 1.482 & 1.137 & 1.930 \\
\hline
\end{tabular}

Data from only those that reported most serious injuries after controlling for Age, Gender and Family Affluence Bold text showing statistically significant results

LTID Long-term illnesses or disabilities, MVPA Moderate to vigorous physical activities

n (Sample size), OR (Adjusted Odds Ratio), Lower Cl (Lower 95\% Confidence Interval), Upper Cl (Upper 95\% Confidence Interval)

make comparisons between LTID groups possible. In many cases, pupils who attend these schools have lower severity of disabilities than those that would require special educational support in special schools. Despite these population differences, the adolescents in this study still had greater odds of injuries over their peers without LTID.

In all cases of the various LTID classifications, there were greater odds of reporting injuries. Other studies on injuries of children with chronic conditions, functional disabilities and intellectual disabilities have reported similar results (Shi et al. 2015; Ramirez et al. 2004). Although caution when interpreting the results is needed, as often there is a lack of information regarding the types of LTID. In an attempt to overcome these limitations, items related to health conditions and functional difficulties were incorporated into the 2014 Finnish data collection round. Functional impairments may put the adolescent at risk for injuries in general, such as knocking into things and falling down with visual impairments, unable to hear warning sounds for adolescents with hearing difficulties, as well as delayed movement to a safe place when there is a danger. Comorbidity can increase the odds up to three fold when adolescents reported to have chronic conditions, learning and functional difficulties. This may be related to the way the adolescents' process information about their environment and avoid vulnerable situations.

\section{Contextual factors associated with sports related injuries}

The second part of the study was to investigate sports related injuries in relation to degrees of LTID, sports club membership, physical competence, and family encouragement, after controlling for, gender, age and family affluence. Other studies have claimed that athletes with LTID that take part in organised sports have lower exposure to injury (Ramirez et al. 2009). Through the performed analyses, we complemented these earlier findings. Adding to the literature, in Ramirez's study (Ramirez et al. 2009), the researchers followed special education interscholastic league for the course of a season. In recent years, there has been an increase in overall PA in adolescents with LTID (Ng et al. 2016b) and the amount of activities targeted for children that attend special education in Finland (Mononen et al. 2014). However, studies like these often fail to report whether children that attend these activities are part of the mainstream school system, hence providing addition information to this phenomena.

While there was weak evidence to suggest that there are differences in the amounts of physical activity, sports club membership and physical competence between adolescents with and without LTID, there seem to be a difference if the adolescent has affected LTID. Previous research suggests that a low exposure to physical activities shows low levels of sports related injuries (Raman et al. 2007), and in our study, approximately half of 
adolescents with affected LTID were likely to report their main injury to have taken place during sports. Adolescents with affected LTID may have functional difficulties, learning difficulties or chronic conditions that affect their participation and these elevated risks of injuries may be from serious non-sports related events.

In the opposite direction of the low exposure and low risk association, sports club members were between four and seven times more likely to report sports related injuries. This was expected as the exposure to activities is greater than non-members. Furthermore, adolescents with high physical competence are twice likely to experience sports related injuries. High physical competence, is not an indicator of actual performance, but linked to high confidence to perform (Kipp \& Weiss 2013). Athletes may then be at a greater risk of sport injuries.

After adjusting for sports club membership, and daily physical activities, adolescents with affected LTID were less likely to report sports related injuries than adolescents without LTID. In other research, non-organised sports produces nearly twice as many injuries as in the organised sports setting (Zaricznyj et al. 1980), and this may be an incentive for people at risk of injuries to attend sports clubs rather than to pursue their own activities as recent trends have shown ( $\mathrm{Ng}$ et al. 2016b). Sport clubs have a responsibility to adhere to safety promotion guidelines. More research on the effectiveness of such guidelines after taking into considering the inclusion of disabilities in sports club is needed. Creating an inclusive environment for athletes to support each other regardless of disabilities may encourage more membership among affected LTID adolescents. Yet, the steps for clubs to do this can take many years to develop as the many club settings are run by volunteers (Geidne et al. 2012; Kokko 2014).

\section{Strengths and limitations}

This study has a number of strengths and limitations that the reader may like to consider when interpreting the results of the study. The HBSC survey has collected national representative data since 1983. No statistical weights were applied since, no formal register of disability statistics in schools is currently available. The sampling procedures do not include special schools, where children with special educational support needs often attend. It is not clear if the classes chosen to complete the questionnaire are representative of the school for the prevalence of LTID. Data collection was anonymous, reducing response bias, but sacrifices class level statistical models. Construct validity of some items remain unknown, for example, the wording of the family encouragement item was originally in Finnish and subsequently translated into English. Contextual meaning may be different from the literal meaning in this item. In addition, the data does not allow for interpretation of the actual meaning of 'serious injury' as perceived among the respondents. There were no items about milder injuries, other locations for sports related injuries, or details of the types of injuries that took place in the sports facilities. In addition, although respondents indicated the place and activity of their most serious injury, there is a lack of clarity in whether the injuries only during sports club activities or other times, such as recreation or in school. Also, lack of specificity on physical activities do not allow differentiation between activities attended during physical therapy, physical education or sport club activities. As such, it could limit the precision of safety promotion messages. Adolescents self-reported their difficulties, and this perception can be hard to quantify when measured against medical standards. Another explanation for the relatively high proportion of adolescents who reported LTID (25\%) was the omission of the words, "please do not include learning disabilities" to be in line with other national surveys such as England, France, Ireland and Portugal (Sentenac et al. 2013). Therefore, it was important to utilise a functional, learning, and symptom based measures to correspond to the ontology of the biopsychosocial model of disability, especially in the associations to injuries. A dedicated survey for disabilities would have been useful to know more about the difficulties, although space, anonymity, and other logistics prevented this.

\section{Conclusions}

Taking part in regular physical activities can improve overall health, but it comes at a risk for injuries in adolescents. It is even more important for adolescents with long-term illnesses or disabilities to consider the risks with the advantages, since inactivity in these children can lead to more health complications. Personal and environmental factors may influence adolescents' reporting of sports related injuries. More strategies are needed to reduce injury rates from sport settings while increasing rates of PA in adolescents with LTID.

\section{Abbreviations}

CCSQ: Chronic conditions short questionnaire; FAS: Family affluence scale; HBSC: Health Behaviour in School-aged Children study; ICF: International Classification of Functioning, Disability and Health; LTID: Long-term illnesses or disabilities; MVPA: Moderate to vigorous intensity physical activity; PA: Physical activities

\section{Acknowledgement \\ The authors would like to acknowledge the Finnish HBSC study team for the assistance in data collection and processing the file.}

\section{Funding}

The 2014 HBSC data collection was funded by the Finland's Ministry of Social Affairs and Health (STM). Funding for this particular study was not applied for. 


\section{Availability of data and materials}

The data from the HBSC study is available upon request from the HBSC data bank, University of Bergen, Norway. For more information about data access, please visit; http://www.uib.no/en/hbscdata.

\section{Authors' contributions}

KN carried out the injury and disability related studies, statistical analysis and drafted the manuscript. JT, as PI of the HBSC study, carried out the data collection and confirmed the statistical analysis for this study. PR and SK participated in the design of this study and coordination and helped to draft the manuscript. LK conceived of the HBSC study, participated in the design of this study, and helped to draft the manuscript. All authors read and approved the final manuscript.

\section{Competing Interests}

The authors declare that they have no competing interests.

\section{Consent for publication}

All participants provided informed consent.

\section{Ethics approval and consent to participate}

The Finnish HBSC study was approved by the Finnish National Board of Education (FNBE) and the Trade Union of Education in Finland at the beginning of the survey in 1984. The way the data has been collected since 1984 has not changed.

\section{Publisher's Note}

Springer Nature remains neutral with regard to jurisdictional claims in published maps and institutional affiliations.

\section{Received: 14 February 2017 Accepted: 7 April 2017}

Published online: 01 May 2017

\section{References}

Bloemen MAT, Backx FJG, Takken T, et al. Factors associated with physical activity in children and adolescents with a physical disability: a systematic review. Dev Med Child Neurol. 2015;57:137-48. doi:10.1111/ dmcn.12624.

Borraccino A, Lemma P, lannotti RJ, et al. Socioeconomic effects on meeting physical activity guidelines: comparisons among 32 countries. Med Sci Sports Exerc. 2009:41:749-56. doi:10.1249/mss.0b013e3181917722.

Chzhen Y, Bruckauf Z, Ng KW, et al. Inequalities in Adolescent Health and Life Satisfaction: Evidence from the Health Behaviour in School-aged Children study 2016; Innocenti Working Papers no. 2016_09.

Currie C, Zanotti C, Morgan A, et al. Social determinants of health and well-being among young people. Health Behaviour in School-aged Children (HBSC) study: international report from the 2009/2010 survey. Copenhagen: WHO-Europe. Health Policy Children Adolesc. 2012;(6).

Dale A, Marsh C. The 1991 Census Users guide. London: HMSO; 1993. p. 415.

de Looze M, Pickett W, Raaijmakers Q, et al. Early risk behaviors and adolescent injury in 25 European and North American countries: a cross-national consistent relationship. J Early Adolesc. 2012;32:104-25. doi:10.1177/ 0272431611414062

Emery CA. Risk factors for injury in child and adolescent sport: a systematic review of the literature. Clin J Sport Med. 2003;13:256-68.

Geidne S, Quennerstedt M, Eriksson C. The youth sports club as a healthpromoting setting: an integrative review of research. Scand J Public Health 2012;41:269-83. doi:10.1177/1403494812473204.

Haugland S, Wold B. Subjective health complaints in adolescence—reliability and validity of survey methods. J Adolesc. 2001;24:611-24. doi:10.1006/jado.2000. 0393.

Inchley J, Currie D, Young T, et al. Growing up unequal: gender and socioeconomic differences in young people's health and well-being. Health Behaviour in School-aged Children (HBSC) Study: International Report from the 2013/2014 Survey; Copenhagen: WHO-Europe. Health Policy for Children and Adolescents. 2016;(7).

Kipp LE, Weiss MR. Physical Activity and self-perceptions among children and adolescents. In: Ekkekakis P, editor. Routledge handbook of physical activity and mental health. Abingdon, Oxon: Routledge; 2013. p. 187-99.
Klugl M, Shrier I, McBain K, et al. The prevention of sport injury: an analysis of 12,000 published manuscripts. Clin J Sport Med. 2010;20:407-12. doi:10.1097/ JSM.0b013e3181f4a99c.

Kokko S. Guidelines for youth sports clubs to develop, implement, and assess health promotion within its activities. Health Promot Prac. 2014;15:373-82. doi:10.1177/1524839913513900.

Lintunen T, Leskinen E, Oinonen $\mathrm{M}$, et al. Change, reliability, stability in selfperceptions in early adolescence: a four year follow-up study. Int I Behav Dev. 1995; 18:351-64.

Mattila V, Parkkari J, Kannus $\mathrm{P}$, et al. Occurrence and risk factors of unintentional injuries among 12- to 18-year-old Finns: a survey of 8219 adolescents. Eur J Epidemiol. 2004;19:437-44. doi:10.1023/B:EJEP. 0000027355.85493.cb.

McDougall J, Miller L. Measuring chronic health condition and disability as distinct concepts in national surveys of school-aged children in Canada: a comprehensive review with recommendations based on the ICD-10 and ICF. Disabil Rehabil. 2003;25:922-39. doi:10.1080/09638280 31000122249.

Mitchell R, Finch C, Boufous S. Counting organised sport injury cases: evidence of incomplete capture from routine hospital collections. J Sci Med Sport. 2010; 13:304-8. doi:10.1016/j.jsams.2009.04.003.

Molcho M, Harel Y, Pickett W, et al. The epidemiology of non-fatal injuries among 11-, 13- and 15-year old youth in 11 countries: findings from the 1998 WHO-HBSC cross national survey. Int J Inj Contr Saf Promot. 2006;13:205-11. doi:10.1080/17457300600864421.

Mononen K, Aarresola O, Sarkkinen P, et al. Tavoitteena Nuoren Urheilijan Hyvä Päivä 2014 [Aims of Youth Athlete's Good Day 2014]. 2014. p. 46.

Ng KW, Rintala P, Tynjälä JA, et al. Physical activity patterns of adolescents with long term illnesses or disabilities in Finnish general education. Eur J Adapt Phys Act. 2014;7:58-72.

Ng KW, Rintala P, Välimaa RS, et al. Daily physical activity in Finnish adolescents with long term illnesses or disabilities:psychosocial associations with participation in sports club. EBPH. 2016;13:e11699-1. doi:10.2427/11699.

Ng KW, Rintala P, Tynjälä JA, et al. Physical activity trends of Finnish adolescents with long-term illnesses or disabilities from 2002 to 2014. J Phys Act Health. 2016b;13:816-21. doi:10.1123/jpah.2015-0539.

Pickett W, Molcho M, Simpson K, et al. Cross national study of injury and social determinants in adolescents. Inj Prev. 2005;11:213-8. doi:10.1136/ip.2004. 007021.

Pittet I, Berchtold A, Akré C, et al. Sports practice among adolescents with chronic health conditions. Arch Pediatr Adolesc Med. 2009;163:565-71. doi:10.1001/archpediatrics.2009.49.

Prochaska JJ, Sallis JF, Long B. A physical activity screening measure for use with adolescents in primary care. Arch Pediatr Adolesc Med. 2001;155:554-9. doi:10.1001/archpedi.155.5.554.

Raman SR, Boyce WF, Pickett W. Injury among 1107 Canadian students with self-identified disabilities. Disabil Rehabil. 2007;29:1727-35. doi:10.1080/ 09638280601129231.

Ramirez M, Peek-Asa C, Kraus JF. Disability and risk of school related injury. Inj Prev. 2004;10:21-6. doi:10.1136/ip.2003.002865.

Ramirez M, Yang J, Bourque L, et al. Sports injuries to high school athletes with disabilities. Pediatrics. 2009;123:690-6. doi:10.1542/peds.2008-0603.

Rimmer JH, Schiller W, Chen M. Effects of disability-associated low energy expenditure deconditioning syndrome. Exerc Sport Sci Rev. 2012;40:22-9. doi:10.1097/JES.0b013e31823b8b82.

Roberts C, Freeman J, Samdal O, et al. The Health Behaviour in School-aged Children (HBSC) study: methodological developments and current tensions. Int J Public Health. 2009;54:140-50. doi:10.1007/s00038-009-5405-9.

Scheidt PC, Harel Y, Trumble AC, et al. The epidemiology of nonfatal injuries among US children and youth. Am J Public Health. 1995;85:932-8.

Selb M, Escorpizo R, Kostanjsek N, et al. A guide on how to develop an International Classification of Functioning, Disability and Health Core Set. Eur J Phys Rehab Med. 2015;51:105-17.

Sentenac M, Mazur J, Gavin A, et al. Disability and chronic conditions 2013;HBSC 2013-2014 Protocol - Appendix 5/3.

Shi X, Shi J, Wheeler KK, et al. Unintentional injuries in children with disabilities: a systematic review and meta-analysis. Inj Epidemiol. 2015;2:1-13. doi:10.1186/ s40621-015-0053-4.

Torsheim T, Cavallo F, Levin KA, et al. Psychometric validation of the revised family affluence scale: a latent variable approach. Child Indic Res. 2015;9:771-84. doi:10.1007/s12187-015-9339-X. 
Vuori MT, Kannas LK, Tynjälä JA. Nuorten liikuntaharrastuneisuuden muutoksia 1986-2002 [Changes in youth sport club activities 1986-2002]. In: Kannas LK editor. Koululaisten terveys ja terveyskäyttöytyminen muutoksessa; WHOKoululaistutkimus 20 vuotta, [Changes in school-aged children's health and health behaviours; HBSC 20 years]. Jyväskylä, Finland: University of Jyväskylä; 2004. p. 113-40.

Vuori MT, Ojala SAK, Tynjälä JA, et al. Liikunta-aktiivisuutta koskevien kysymysten stabiliteetti WHO-koululaistutkimuksessa. The stability of questions concerning physical activity in the HBSC study.]. Liikunta \& Tiede. 2005;42:39-46.

WHO. International Classification of Functioning, Disability and Health (ICF). Geneva, Switzerland: World Health Organization; 2001.

WHO. Global recommendations on physical activity for health. Geneva: World Health Organization; 2010

Zaricznyj B, Shattuck LJM, Mast TA, et al. Sports-related injuries in schoolaged children. Am J Sports Med. 1980;8:318-24. doi:10.1177/ 036354658000800504

\section{Submit your manuscript to a SpringerOpen ${ }^{\circ}$ journal and benefit from:}

- Convenient online submission

- Rigorous peer review

- Immediate publication on acceptance

- Open access: articles freely available online

- High visibility within the field

- Retaining the copyright to your article

Submit your next manuscript at $\gg$ springeropen.com 